\title{
Stability Indicating Stress Degradation Study of Orlistat by UV Spectrophotometry Method
}

\author{
Gade Mukund Maruti ${ }^{1 *}$, Bhanwase Anil Subhash ${ }^{1}$, Hurakadle Pramod Jaydevappa ${ }^{2}$ \\ 'Department of Pharmaceutics, Shikshan Prasarak Mandal College of Pharmacy, Malewadi, Akluj, Maharashtra, INDIA. \\ ${ }^{2}$ Department of Pharmaceutical Biotechnology, KLE University's College of Pharmacy, Belagavi, Karnataka, INDIA.
}

\begin{abstract}
Objectives: To study the stress degradation behavior of an orlistat by UV spectrophotometric method. Methods: An accurate, simple and rapid UV spectrophotometric method for orlistat was developed and used in phosphate buffer $\mathrm{pH} 8$. The method is validated for linearity, precision and accuracy. Stress degradation study was performed at alkaline, acid, neutral and photolytic conditions. Results: Linearity was found to be $8-28 \mu \mathrm{g} / \mathrm{ml}$. Absorbance showed at different concentrations was found to be linear with the correlation coefficient 0.999 . The Intra-day and Inter-day precision studies were carried out. The relative standard deviation was found to be 0.0029 and 0.0095 for Intra-day and Inter-day precision studies respectively. Orlistat was found to be degraded in acidic, alkaline, neutral and oxidative stress conditions whereas it was found to be stable in light. The LOD and $\mathrm{LOQ}$ of the developed method were found to be $0.3444 \mu \mathrm{g} / \mathrm{ml}$ and $1.0740 \mu \mathrm{g} /$ $\mathrm{ml}$ respectively. Accuracy was studied by the recovery method. Percentage accuracy was found to be $96.19 \% \pm 0.99 \%$. The decrease in absorbance was observed at $1 \mathrm{~h}$, which concludes the degradation of the drug in acidic stress conditions. The drug was found to be unstable in alkaline conditions.
\end{abstract}

The results revealed that degradation products are having more absorbance than the drug. The 5 is slight decrease in absorbance was observed at $1 \mathrm{~h}$, which remained constant after $4 \mathrm{~h}$. also method showed its usefulness in analyzing marketed samples of orlistat formulations. Conclusion: From the obtained results, it can be concluded that the developed method is simple and economic. It can be successfully used for the stress degradation studies; hence, it can be applied for routine analysis in the industry. Key words: Orlistat, Stress degradation, UV spectrophotometry.

Correspondence

Dr. Gade Mukund Maruti,

Department of Pharmaceutics, Shikshan Prasarak Mandal College of Pharmacy, Malewadi, Akluj-413101, Maharashtra, INDIA.

Phone: +919975865649

Email: mukundgade09@gmail.com

DOI: 10.5530/jyp.2020.12.25

\section{INTRODUCTION}

Orlistat is widely used as an antiobesity agent. Chemically it is [(1S)-1-[(2S, 3S)-3-hexyl-4-oxo-oxetan -2-yl] methyl] dodecyl] (2S)-2-formamido4-methyl-9 pentonate also known as tetrahydrolipstatin. It is saturated derivative of the lipstatin a potent natural inhibitor of pancreatic lipase, isolated from the bacterium Streptomyces toxytricini. It acts by binding covalently with serine residue of the enzyme. On oral administration of orlistat with fat containing food, it hydrolyses triglyceride which reduces the absorption of monoacylglycerides and free fatty acids in to the body. ${ }^{1}$

Determination of drug content in bulk and marketed formulation is essential step to confirm its purity and stability. To estimate drug content, simple and economic analytical method is required. In case of orlistat, few HPLC (High Performance Liquid Chromatography) methods are reported in literature. Stability indicating high performance liquid chromatographic method was developed to determine orlistat content in bulk and its degradation products. ${ }^{2}$ Detection of the SSR impurity of orlistat in capsule by high performance liquid chromatographic method was reported. ${ }^{3}$ The new RP-HPLC method was reported to determine orlistat in bulk and pharmaceutical dosage form. ${ }^{4}$ For the quality control of Orlistat HPLC method was reported. ${ }^{5}$ There are some UV methods which are not reproducible. In case of HPLC method, it is costlier, not easily available and it requires skilled personnel to handle it. As compared to the HPLC method UV method is easy to perform and economical too. Stability-indicating stress degradation studies of Lafutidine using UV spectrophotometric method was carried out. ${ }^{6}$ Stress degradation study is performed as per ICH guideline at different stress conditions. ${ }^{7}$ From the literature review, it has been revealed that there is no stress degradation study has been carried out by UV spectrophotometry method. However, there are certain limitations of the UV method such as, it is not possible to identify the impurity. Hence, major objective of the study was to develop UV method and to study stress degradation behavior of orlistat in different stress conditions.

\section{MATERIALS AND METHODS}

\section{Instruments and materials}

UV spectrophotometer (Inkarp - Sican 2301) was used. Orlistat was kind gift by the Biocon limited, Banglore India. All chemicals and reagents used were of analytical grade.

\section{Preparation of standard stock solution}

Standard stock solution of $400 \mu \mathrm{g} / \mathrm{ml}$ concentration was prepared by using methanol as solvent. It was filtered through whatmann filter paper \#41 and used to prepare further dilutions.

\section{Preparation of sample solutions}

Aliquots of stock solution were subjected to serial dilutions with phosphate buffer $\mathrm{pH}-8$ to get solutions with concentration of $8-28 \mu \mathrm{g} / \mathrm{ml}$.

\section{Determination of $\lambda_{\max }$}

The wavelength of maximum absorbance $\left(\lambda_{\max }\right)$ of the drug was determined by scanning the drug solution with concentration $20 \mu \mathrm{g} / \mathrm{ml}$ in range of $800 \mathrm{~nm}-199 \mathrm{~nm}$. The drug solution was showing absorption maxima at 


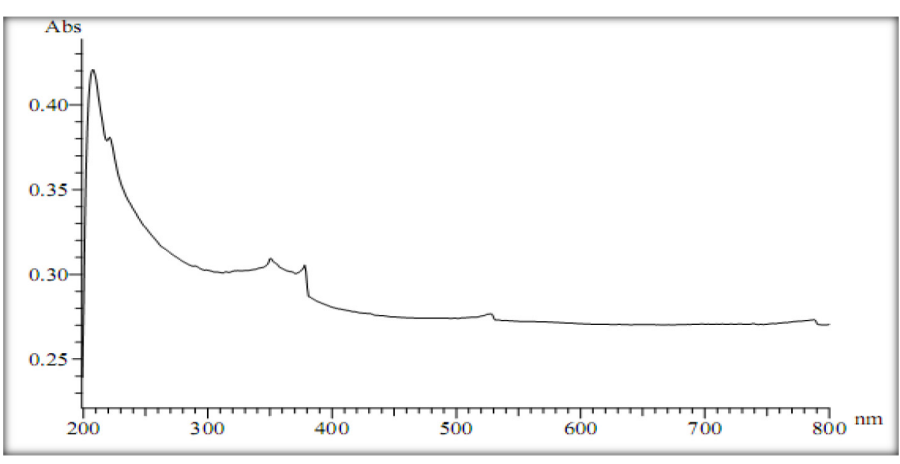

Figure 1 : UV spectrum of drug solution in Phosphate buffer $\mathrm{pH}-8$.

$205 \mathrm{~nm}$, so this wavelength was considered for further study. The UV spectrum of the drug solution is as shown (Figure 1).

\section{Validation of method}

\section{Linearity}

The linearity of measurements was evaluated by analyzing orlistat at different concentration. The calibration curve was obtained by plotting the absorbance versus the concentration data and was treated by linear regression analysis.

\section{Precision}

The precision of the method was studied in terms of intra-day changes in absorbance of drug solution on the same day and inter-day changes on three different days over a period of one week. The Intra-day and Inter-day variations were calculated in terms of standard deviation.

\section{Limit of Detection (LOD) and Limit of Quantification (LOQ)}

The LOD and LOQ were calculated by standard deviation of the response and slope of the calibration curve. The formula for the LOD and LOQ are as follows

$$
\begin{aligned}
& \mathrm{LOD}=\frac{3.3 \sigma}{\mathrm{s}} \\
& \mathrm{LOQ}=\frac{10 \sigma}{\mathrm{s}}
\end{aligned}
$$

Where $\sigma=$ Standard deviation of the response,

$$
\mathrm{s}=\text { Slope of the calibration curve }
$$

\section{Accuracy (recovery method)}

Accuracy of method was studied by recovery method. Recovery experiment was carried out by adding known amount of pure drug in powder mixture from capsule. Orlistat was added in level of $80 \%, 100 \%$ and $120 \%$. Three samples for each level were analyzed and \% recovery was calculated.

\section{Analysis of marketed capsule formulations}

The developed UV spectrophotometric method was used to determine orlistat content into the commercially available marketed formulation of orlistat (OrLean 60-Eris Lifesciences Pvt.Ltd.). Ten capsules were weighed and contents from capsule were obtained by removing capsule shell. Further, contents were mixed uniformly by using mortar and pestle. Quantity equivalent to $10 \mathrm{mg}$ of orlistat was weighed and transferred it into the $25 \mathrm{ml}$ of volumetric flask containing $15 \mathrm{ml}$ of methanol it was kept for 15 min with frequent shaking. Further volume was made up with the methanol and it was subjected for sonication on bath sonicator for $10 \mathrm{~min}$. The solution was filtered through Whatman Filter Paper \#41. This filtrate was diluted to get solution of the $20 \mu \mathrm{g} / \mathrm{ml}$ concentration.
The absorbance was measured against blank solution. Orlistat content of capsule was calculated using standard calibration curve. In addition, drug content was estimated in O-stat 60 (Aristo Pharmaceuticals Pvt. Ltd.).

\section{Forced degradation study}

\section{Acid and alkali degradation}

Acid degradation was performed into the $0.1 \mathrm{~N}, 0.2 \mathrm{~N}, 0.5 \mathrm{~N} \mathrm{HCl}$ and alkali degradation was carried out in $0.1 \mathrm{~N}$ and $0.2 \mathrm{~N} \mathrm{NaOH}$. The concentration of $20 \mu \mathrm{g} / \mathrm{ml}$ orlistat was used for the degradation studies. Absorbance was measured at initial, $1^{\text {st }}, 2^{\text {nd }}, 3^{\text {rd }}$ and $4^{\text {th }} \mathrm{hr}$.

\section{Neutral hydrolysis}

To study degradation of orlistat in neutral conditions distilled water was used as solvent. Initially orlistat was dissolved in methanol and dilutions were made with distilled water.

\section{Hydrogen peroxide degradation}

Oxidative degradation was carried out by using 3\% v/v and $30 \% \mathrm{v} / \mathrm{v}$ hydrogen peroxide solutions as solvents. The samples were withdrawn at predetermined time intervals and analyzed after suitable dilutions at $205 \mathrm{~nm}$.

\section{Photolytic degradation}

Photolytic degradation was carried out by directly exposing orlistat to the sunlight during day time (60,000-70,000 lux) for 2 days.

\section{RESULTS}

\section{Validation of method}

Linearity was found to be $8-28 \mu \mathrm{g} / \mathrm{ml}$. Absorbance showed at different concentration was found to be linear with correlation coefficient 0.999 (Table 1). The Intra-day and Inter-day precision studies were carried out. The relative standard deviation was found to be 0.0029 and 0.0095 for Intra-day and Inter-day precision studies respectively. Intra-day and Inter-day precision is as shown in (Table 2). The LOD and LOQ of the developed method were found to be $0.3444 \mu \mathrm{g} / \mathrm{ml}$ and $1.0740 \mu \mathrm{g} / \mathrm{ml}$ respectively. Accuracy was studied by recovery method. Percentage accuracy was found to be $96.19 \% \pm 0.99 \%$ (Table 3 ).

\section{Stress degradation study}

Acid degradation was performed into the $0.1 \mathrm{~N}, 0.2 \mathrm{~N}, 0.5 \mathrm{~N} \mathrm{HCl}$ and alkali degradation was carried out in $0.1 \mathrm{~N}$ and $0.2 \mathrm{~N} \mathrm{NaOH}$. Absorbance of the solution was measured at the $205 \mathrm{~nm}$. From the Figure 2 decrease in absorbance was observed at $1 \mathrm{~h}$ which concludes degradation of the drug in acidic stress condition. The drug was found to be unstable in alkaline condition. It showed absorbance 2.959 and 2.824 in $0.1 \mathrm{~N}$ and $0.2 \mathrm{~N} \mathrm{NaOH}$ respectively. The results revealed that, degradation products are having more absorbance than drug. The neutral degradation was performed. More than 50\% decrease in the absorbance was observed (Figure 2). It was found that orlistat is degraded within $1 \mathrm{~h}$ on neutral hydrolysis. ${ }^{5}$ Oxidative degradation was carried out by using $3 \% \mathrm{v} / \mathrm{v}$ and $30 \% \mathrm{v} / \mathrm{v}$ of hydrogen peroxide. Absorbance was increased up to the 10 which may due to the large amount of impurities produced after oxidation. Photolytic degradation study was carried out. Slight decrease in absorbance was observed at $1 \mathrm{~h}$ which remained constant after $4 \mathrm{~h}$. No extensive change in absorbance was measured.

\section{Analysis of marketed capsule formulation}

Analysis of two marketed formulations (O-STAT60 and OrLean- 60) was carried out by using developed method. Table 4 indicates the amount of orlistat in capsule samples was meeting requirement (95-105\%) of label claim. 
Table 1: Validation parameters.

\begin{tabular}{cc}
\hline Parameters & UV method observations \\
\hline$\lambda_{\max }(\mathrm{nm})$ & 205 \\
Linearity range $(\mu \mathrm{g} / \mathrm{ml})$ & $8-28$ \\
Regression equation & $\mathrm{y}=0.027 \mathrm{x}-0.113$ \\
Correlation coefficient $\left(\mathrm{r}^{2}\right)$ & 0.999 \\
LOD $(\mu \mathrm{g} / \mathrm{ml})$ & 0.3444 \\
LOQ $(\mu \mathrm{g} / \mathrm{ml})$ & 1.0740 \\
\hline
\end{tabular}

Table 2: Results of precision study.

\begin{tabular}{cccc}
\hline Sr No & $\begin{array}{c}\text { Concentration } \\
(\mu \mathrm{g} / \mathrm{ml})\end{array}$ & Intra-day & Inter-day \\
\hline 1 & 20 & 0.400 & 0.385 \\
2 & 20 & 0.401 & 0.391 \\
3 & 20 & 0.394 & 0.401 \\
4 & 20 & 0.402 & 0.395 \\
5 & 20 & 0.401 & 0.405 \\
6 & 20 & 0.400 & 0.38 \\
Average & - & 0.400 & 0.39 \\
Standard Deviation & - & 0.0029 & 0.0095 \\
\hline
\end{tabular}

Table 3: Accuracy study by recovery method.

\begin{tabular}{|c|c|c|c|c|c|c|c|}
\hline 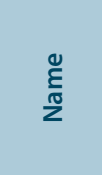 & 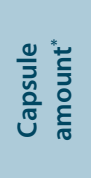 & 范 & 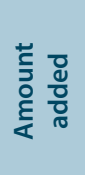 & 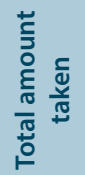 & 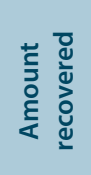 & 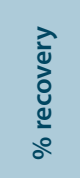 & 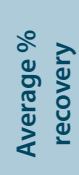 \\
\hline \multirow[t]{3}{*}{ Orlistat } & 10 & 80 & 8 & 18 & 17.11 & 95.07 & \\
\hline & 10 & 100 & 10 & 20 & 19.39 & 96.98 & 96.19 \\
\hline & 10 & 120 & 12 & 22 & 21.23 & 96.53 & \\
\hline
\end{tabular}

*-Amount equivalent to pure orlistat

Table 4: Orlistat content in marketed formulations.

\begin{tabular}{cccc}
\hline \multicolumn{4}{l}{ Table 4: Orlistat content in marketed formulations. } \\
\hline Brand & Label claim & Amount found (Mean \pm SD, mg) & $\%$ Drug \\
\hline O-STAT60 & 60 & $58.89 \pm 0.3$ & 98.15 \\
OrLean- $60^{\circ}$ & 60 & $57.79 \pm 0.4$ & 96.31 \\
\hline
\end{tabular}

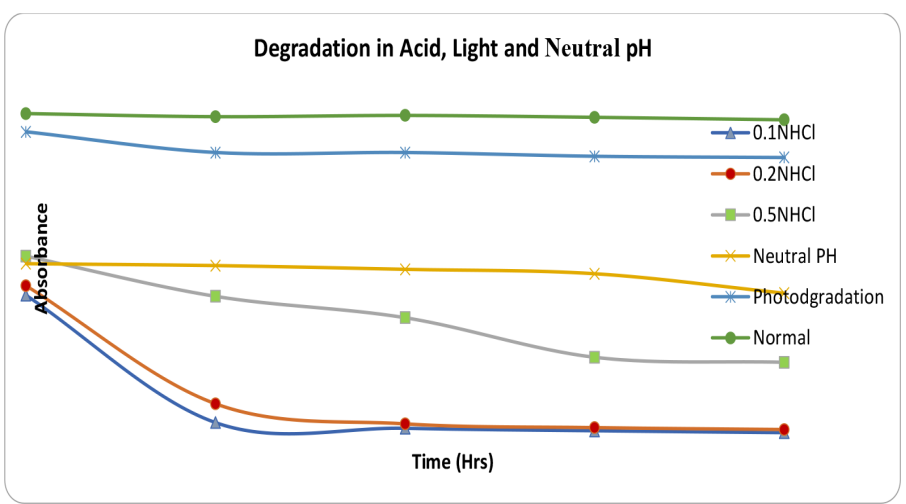

Figure 2: Degradation of orlistat in Acid, Light and Neutral pH.

\section{DISCUSSION}

The standard stock solution was prepared with concentration $400 \mu \mathrm{g} / \mathrm{ml}$ by using methanol as solvent where, orlistat was found to be soluble. The solution was found to be clear, after filtration through Whatman filter paper \#41, which was used for further dilutions.

The sample solutions concentration range was decided by scanning single dilution of concentration $20 \mu \mathrm{g} / \mathrm{ml}$. The serial dilutions were carried out by using phosphate buffer $\mathrm{pH}-8$ to get solutions with concentration of $8-28 \mu \mathrm{g} / \mathrm{ml}$. The wavelength of maximum absorbance $\left(\lambda_{\max }\right)$ of the drug was found to be $205 \mathrm{~nm}$ when the solution was scanned at concentration $20 \mu \mathrm{g} / \mathrm{ml}$. here the highest absorbance is observed at $205 \mathrm{~nm}$. Hence, $205 \mathrm{~nm}$ wavelength was considered for further study. Souri et al. and Nama et al. detected orlistat at $205 \mathrm{~nm}$ wavelength in their study. So, results obtained in this study are found to be in correlation with reported study. ${ }^{4,5}$ The absorbance of individual concentration was determined at $205 \mathrm{~nm}$ wavelength. Here, absorbance was found to be increased in linear manner hence, method was found to be linear. The correlation coefficient supported linearity of the method as it is near to unity. To check the correctness of the method, the drug solution with specific concentration $(20 \mu \mathrm{g} / \mathrm{ml})$ was prepared and its absorbance was recorded at different time interval in a day and on different days. The intra-day and inter-day precision indicated correctness of method.

The Limit of Detection (LOD) and Limit of Quantification (LOQ) help to determine the sensitivity of the method, which is determined with deviation. From the LOD and LOQ study, it is observed that, the developed method can determine presence of drug and quantify it at very low concentration. The recovery analysis revealed that developed method was able to detect externally added known concentration of drug. It is evidenced that the method is accurate.

\section{Accuracy of method was studied by recovery method}

To evaluate the applicability of the developed analytical method at commercial scale it is applied and tested for its performance by testing some marketed formulations. The content in the commercially available marketed formulation of orlistat was determined by using developed UV spectrophotometric method. The marketed formulations were analyzed such as OrLean 60 from Eris Lifesciences Pvt.Ltd. and O-stat 60 from Aristo Pharmaceuticals Pvt. Ltd. The developed method, which was used to analyze the marketed samples, results obtained was found to be complying the specifications provided on label. Hence, the developed method was found to be useful in analyzing the commercial product.

The stability can be determined by exposing pure drug or (active pharmaceutical ingredient) at different stress conditions. ${ }^{6}$ From the stress degradation study, it is observed that the decrease in absorbance at $1 \mathrm{~h}$ in acidic media, which concludes degradation of the drug in acidic stress condition. The stress degradation study, carried out in acidic media at $0.1 \mathrm{~N} \mathrm{HCl}$ and $0.2 \mathrm{~N} \mathrm{HCl}$, the sudden fall in absorbance was observed whereas in $0.5 \mathrm{~N} \mathrm{HCl}$ increase in absorbance was observed which is due to the increase in degradation products at highly acidic conditions. The drug was found to be unstable in alkaline condition as the absorbance of the drug supported the evidence. The results revealed that, degradation products are having more absorbance than drug. There is slight decrease in absorbance was observed at $1 \mathrm{~h}$, which remained constant after $4 \mathrm{~h}$. Acid degradation study revealed that degradation of the drug in acidic condition whereas drug was found to be unstable in alkaline condition. The degradation at neutral $\mathrm{pH}$ was showed more than $50 \%$ decrease in the absorbance. Absorbance was increased up to the 10, which may due to the large amount of impurities produced upon oxidation. The photolytic degradation study revealed that slight decrease in absorbance at $1 \mathrm{~h}$, which remained constant after $4 \mathrm{~h}$. 


\section{CONCLUSION}

Stress degradation study was carried out for orlistat at different stress conditions like acid alkali, neutral, photolytic. Developed UV spectrophotometric method was found to be simple and economic. From stress degradation study it was found that, the orlistat was degraded in acid, alkali, neutral stress condition whereas it was not degraded in light. Hence, it is concluded that developed method is applicable for routine analysis in pharmaceutical industry.

\section{ACKNOWLEDGEMENT}

The authors are thankful to Biocon Limited Banglore, India for providing Orlistat as a gift sample. Also authors are thankful to the KLE University Belagavi-10 for providing scholarship to carry out reasearch work.

\section{CONFLICT OF INTEREST}

The authors declare no conflict of interest.

\section{ABBREVIATIONS}

HCl: Hydrochloric acid; $\mathrm{NaOH}$ : Sodium Hydroxide.

\section{REFERENCES}

1. Guerciolini R. Mode of action of orlistat. Int J Obes Relat Metab Disord. 1997;3:12-3.

2. Bindaiya $S$, Argal A. Stability indicating assay of orlistat and its degradation products by HPLC. Bull Pharm Res. 2013;3(2):44-50.

3. Kumar P, Bhanu V, Reddy P, Thiyaharajan S, Palakurthi K, Vinta R, et al. Quantification of SSRR impurity of orlistat in orlistat capsules by normal HPLC UV detector. Int Res J Pharm. 2012;3(4):350-5.

4. Nama S, Chandu B, Khagga M. A new RP-HPLC method development and validation of orlistat in bulk and pharmaceutical dosage forms. Int J Pharma Sci Res. 2010;1(6):251-7.

5. Souri $\mathrm{E}$, Jalalizadeh $\mathrm{H}$, Kebriaee-Zadeh A, Zadehvakili B. Analysis of orlistat and its application to drug quality control studies. Chem Pharm Bull. 2007;55(2):251-4.

6. Jadhav K, Dhamecha D, Asnani G, Patil P, Patil M. Stability-indicating stress degradation studies of lafutidine using UV spectrophotometric method. Pharm Methods. 2013;4(1):21-5.

7. ICH, Q1A (R2). Stability Testing of New Drug Substances and Products IFPMA Geneva. 2003.

Article History: Submission Date : 24-01-2020; Revised Date : 29-02-2020; Acceptance Date : 06-04-2020.

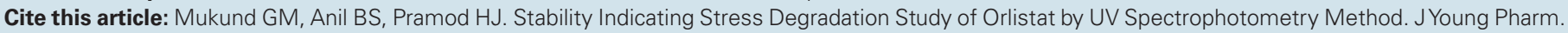
2020;12(2):125-8. 